\title{
Pairomics, the omics way to mate choice
}

\author{
Sergio Ulhoa Dani ${ }^{1}$, Winfried März ${ }^{2}$, Paulo Mauricio Serrano Neves ${ }^{1}$ and Gerhard Franz Walter ${ }^{3}$
}

The core aspects of the biology and evolution of sexual reproduction are reviewed with a focus on the diploid, sexually reproducing, outbreeding, polymorphic, unspecialized, altricial and cultural human species. Human mate choice and pair bonding are viewed as central to individuals' lives and to the evolution of the species, and genetic assistance in reproduction is viewed as a universal human right. Pairomics is defined as an emerging branch of the omics science devoted to the study of mate choice at the genomic level and its consequences for present and future generations. In pairomics, comprehensive genetic information of individual genomes is stored in a database. Computational tools are employed to analyze the mating schemes and rules that govern mating among the members of the database. Mating models and algorithms simulate the outcomes of mating any given genome with each of a number of genomes represented in the database. The analyses and simulations may help to understand mating schemes and their outcomes, and also contribute a new cue to the multicued schemes of mate choice. The scientific, medical, evolutionary, ethical, legal and social implications of pairomics are far reaching. The use of genetic information as a search tool in mate choice may influence our health, lifestyle, behavior and culture. As knowledge on genomics, population genetics and gene-environment interactions, as well as the size of genomic databases expand, so does the ability of pairomics to investigate and predict the consequences of mate choice for the present and future generations. Journal of Human Genetics (2013) 58, 643-656; doi:10.1038/jhg.2013.86; published online 15 August 2013

Keywords: assortative mating; genetic counseling; genomics; mate choice; pair bonding; pairomics

\section{INTRODUCTION}

Sexual reproduction emerged early in the natural history of life on Earth, possibly in pre-cellular ancestors of Gram-negative eubacteria. ${ }^{1,2}$ Sexual reproduction provides for maintenance of genetic diversity through recombination, replication fidelity and viability, meaning that both adaptability and adaptation of organisms and species is increased in a more efficient way than by asexual reproduction. ${ }^{3,4}$

In the human species and other altricial species with highly dependent young, random mating or promiscuity evolved to pair bonding, reflecting the fact that mate choice and pair bonding is central to individuals' lives and to the evolution of the species. ${ }^{5,6}$ Mate choice and pair bonding serve important functions such as securing offspring survival and minimizing inbreeding.?

The genetic underpinnings of mate choice and pair bonding have been intensively studied in a number of animal models including man, and variation in the receptors of oxytocin, vasopressin, dopamine and serotonin has been associated with parenting behavior, social recognition, affiliative behaviors and pair bonding. ${ }^{8}$ Further genetic and nongenetic factors underlying variation in mate choice and pair bonding are poorly understood.

In our species, physical and mental traits such as age, body size and shape, intelligence, personality and social behavior, as well as cultural factors such as ethnicity, religiosity, socioeconomic and educational status contribute in the multicued mate choice process. ${ }^{9-15}$ The use of multiple cues can reduce mate choice costs by decreasing the number of mates inspected more closely or the time and energy spent inspecting a set of mates. ${ }^{16}$ This sophisticated mate choice process has influenced our reproductive outcomes and evolution ${ }^{17-20}$ in a way that has been described as 'dual inheritance' or 'gene-culture coevolution.' ${ }^{21-23}$

Some widespread mating preferences have been shown to have significant impacts on not only fitness, but also disease burden in human societies. For example, men place more importance on youthfulness and fertility than do women, who regard resourceholding potential as a more relevant criterion. ${ }^{24}$ Although paternal age of reproduction is associated with telomere length and increased lifespan in the offspring, ${ }^{25-28}$ lower maternal reproductive age is a factor in the evolutionary maintenance of female reproductive senescence and menopause. ${ }^{29}$

In the last few decades, genetic counseling, artificial fertilization (AI), in vitro fertilization (IVF), preimplantation diagnosis (PID), and prenatal diagnosis (PND) have added new tools and cues to human reproduction and evolution. Thanks to these new tools, a number of genes that have been found to cause genetic diseases such as hemochromatosis, phenylketonuria, cystic fibrosis, spinal muscular

${ }^{1}$ Medawar Institute for Medical and Environmental Research, Acangau Foundation, Paracatu, Brazil; ${ }^{2}$ Mannheim Institute of Public Health, Social and Preventive Medicine, Mannheim Medical Faculty, University of Heidelberg, Mannheim, Germany and ${ }^{3}$ International Neuroscience Institute, Hannover, Germany

Correspondence, Current address: Dr SU Dani, Department of Psychiatry and Psychotherapy, Eberhard Karls University Tübingen, Calwerstrasse 14 , 72076 Tübingen, Baden-Württemberg, Germany.

E-mail: srgdani@gmail.com

Received 13 April 2013; revised 17 June 2013; accepted 3 July 2013; published online 15 August 2013 
atrophy and Tay-Sachs disease can be identified, avoided by gamete choice (AI and IVF) or discarded through embryo selection or abortion following PID or PND, respectively. Also, human leukocyte antigen/major histocompatibility complex genotyping has been widely employed to cross-match donors to recipients in cell, tissue and organ transplantation, ${ }^{30-33}$ and the complete replacement of defective oocyte mitochondrial DNA with normal mitochondrial DNA is now technically possible. ${ }^{34,35}$ It is thus a matter of time and societal acceptance that genomic tools may also be employed in human mate choice.

Herewith, we propose the term 'pairomics' to designate the emerging branch of omics science devoted to the study of mate choice at the genomic level and its consequences for present and future generations. In pairomics, comprehensive genetic information of individual genomes is stored in a database. Computational tools are employed to analyze the mating schemes and rules that govern mating among the members of the database. Mating models and algorithms simulate the outcomes of mating any given genome with each of a number of genomes represented in the database. The analyses and simulations may help to understand mating schemes and their outcomes, and also contribute a new cue to the multicued schemes of mate choice.

\section{DECREASING THE ODDS OF INHERITED GENETIC DISEASES BY PAIROMICS}

Prevention of genetic diseases ought to be the strongest argument for pairomics. A large part of genetic diseases is caused by single genes that are inherited from one or both of the parents. However, one cannot always be certain about the odds of inheritance and manifestation of malfunctioning genes, for reasons pertaining to genetics, epigenetics, environment and gene-environment relationships including nutritional, health, social and lifestyle variables.

Human polymorphism is perhaps the most important of such reasons. Assuming conservatively that (1) 25000 functional genes exist in our genome; (2) all genes are polymorphic; and (3) $99 \%$ of the individuals are homozygous for the commonest allele in each locus, then the probability, $P$, of any individual having 'normal' alleles for each gene is given by Equation (1) as:

$$
\mathrm{P}=0.99^{25,000}
$$

This purely mathematical reasoning allows us to state, with a high degree of certainty, that the odds of any individual having 'normal' alleles in all gene loci are negligible. A number of 'abnormal' alleles may cause genetic diseases, and each one of us is on the brink of manifesting at least one, and probably a couple, of genetic diseases at certain time points of our lives. As we may have inherited the genes responsible for these diseases from our ancestors, we may also pass these genes, gene combinations or gene status to our offspring if we are not reproductively affected by the diseases.

Factors such as heterozygosity, interactions between genotypes at multiple loci (epistasis), genomic redundancy and functional overlap, interactions between genotypes and environment, abiotropy, lifestyle, metabolism and more stochastic genetic events such as transposition, as well as epigenetic events such as methylation and covalent histone modifications may mask the effects of malfunctioning genes (Figure 1). Exhaustive observations in gene-disruption experiments in plant and animal models have shown that a great part of loss-offunction mutations are compatible with the development of viable organisms. Also, some loss-of-function mutations known or suspected to cause disease may confer adaptability under certain environmental conditions, the classical example being the

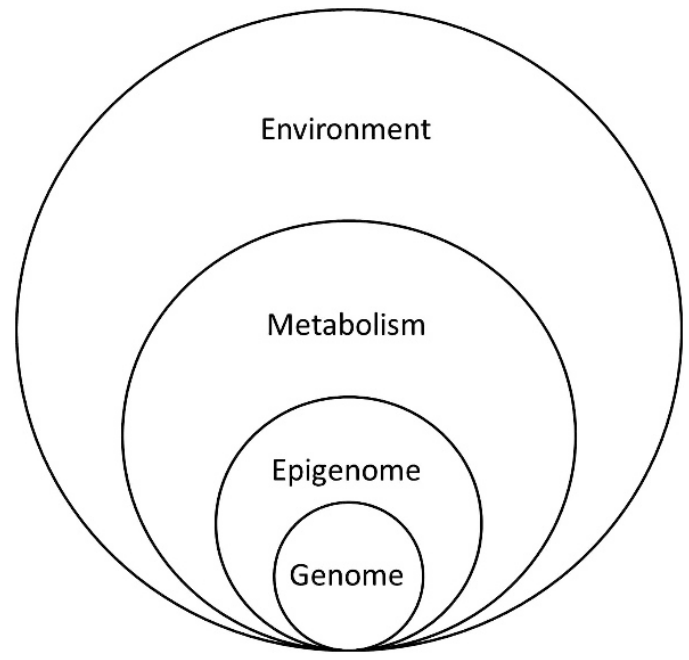

Figure $1 \mathrm{~A}$ field representation of the forces acting upon the genome to determine the phenotype.

reproductive advantage enjoyed by carriers of certain mutations causing hemoglobinopathies or thalassemias in populations living in regions of the world where malaria is endemic. ${ }^{36}$ In fact, a number of diverse disease phenotypes including cancer ${ }^{37,38}$ and metabolic disease $^{39}$ can be compensated for by suppressor mutations.

In consequence, the number of undiagnosed patients and carriers is high, meaning that available epidemiological data on genetic diseases represent a minimum prevalence. The inheritance and manifestation of human genetic diseases are usually described in stratified populations where the underlying mutations have appeared in the homozygous/compound heterozygous/hemizygous state required to manifest a clinical phenotype. ${ }^{40,41}$ Population stratification caused by ethnic, geographical, religious or social divisions is common in human societies; it results in an excess in the proportion of spouse pairs with the same genotypes at all ancestrally informative markers, resulting in ancestrally related positive assortative mating and homozygosis. ${ }^{42}$ Homozygosis has the potential to increase the incidence of recessive diseases in a population. Of the 7028 human disorders with suspected Mendelian inheritance, 1139 are recessive and have an established molecular basis. ${ }^{43}$ The number with a known molecular basis is rapidly increasing through next-generation sequencing (NGS) of whole genomes and exomes of affected individuals. $^{44}$

In a 2011 study employing NGS to sequence 7717 regions from 437 target genes, the genomic carrier burden for severe pediatric recessive disorders ranged from 0 to 7 , averaging 2.8 mutations per capita. ${ }^{43}$ If our genome conceals some 25000 genes, then there would be, on average, 160 recessive mutations per capita, which is in general agreement with an estimate made 55 years ago by Morton et al., ${ }^{45}$ according to whom 'every individual must be heterozygous for many genes which would be seriously deleterious if homozygous and which together probably produce an appreciable loss of fitness even in the heterozygote'. The numbers of 'deleterious' variants that have been reported from the different genomes studied to date are remarkably similar, and these numbers were between one and two orders of magnitude larger than those arrived at via theoretical considerations. ${ }^{46}$ The explanation for this discrepancy is that the latter were focused upon recessive (or null) mutations.

Both recessive and dominant mutations at coding sequences and variation at the noncoding, regulatory and 'junk' sequences of our 
genomes are important causes of disease. Studies of evolutionarily conserved noncoding sequences have suggested that $5-20 \%$ of the genome may be of functional importance, ${ }^{47-50}$ and transposonderived sequences account for at least $40 \%$ of the human genome, a hefty proportion when compared with the $1-2 \%$ given over to protein coding sequences. ${ }^{51}$ Members of active retrotransposon families have been associated with germline insertional mutagenesis and disease ${ }^{52}$ and can also drive somatic genome mosaicism. ${ }^{53}$

With the progress of medicine, it is anticipated that a number of genetic diseases will be treatable and the fitness of the individuals with these diseases will eventually be maintained, though presumably at the expense of some sort of diagnostics and medication. Given the magnitude of carrier burden and the lower cost of testing compared with treating these conditions, it is now generally accepted that carrier screening by NGS made available to the general population may be an economical way to reduce the incidence of, and ameliorate suffering associated with, severe genetic disorders.

It is technically possible to significantly reduce the odds of passing malfunctioning alleles or malfunctioning combinations thereof to our offspring, but our capacity for doing so clearly depends on our ability to understand what is going on in our genetic system, genetic architecture and population genetic structure, as well as in our environment, lifestyle and gene-environment relationships.

\section{Lessons from inbreeding and outbreeding populations}

In a wide range of plant and animal species including man, it has been shown that consanguinity or inbreeding - meaning mating between members of the same family, such as first-cousin marriages, or closely related members in a population-usually increases the incidence of a number of recessive genetic diseases and decreases adaptability and survival, expressed as biochemical, functional and anatomical defects that produce lethal and nonlethal disease, at least for 'adaptations that have not yet stood the test of geological time. ${ }^{54}$ This phenomenon is termed inbreeding depression. Inbreeding depression has important implications for a wide range of biological phenomena, such as inbreeding avoidance, the evolution and maintenance of sexual systems and extinction rates of small populations. ${ }^{55}$

Inbreeding depression obtrudes because inbreeding favors the occurrence of genes in homozygosity, defined by the presence of two identical copies or alleles of the homologous DNA segment in the diploid state. Inconsistencies with regard to associations of homozygosities in some diseases but not others indicate that the effects of homozygosity on the risk of complex phenotypes are disease or trait dependent. ${ }^{56}$ Some homozygosities will sometimes be harmful, so that the inbred stock (if it survives the effects of inbreeding at all) will be at some disadvantage as compared with the outbred population in which harmful genes are masked by the dominance of 'adapted-type' or 'wild-type' genes.

Individuals carrying two malfunctioning copies (non-adapted mutant alleles, in the sense of mutations that reduce adaptation) arise most frequently as the offspring of heterozygous parentsparents who each possess one normal allele ('wild type' or 'adapted type') and one mutant allele (Figure 2). In most cases, the parents are perfectly healthy because the mutant allele has no adverse effect when a normal allele is also present. The parents are said to be carriers of the harmful gene.

Inbreeding depression represents just the deleterious homozygosity end in a spectrum of phenotypic change defined by genome-wide haplotype variation. At the opposite end of this spectrum is the hybrid vigor effect or heterosis, defined by genome-wide beneficial

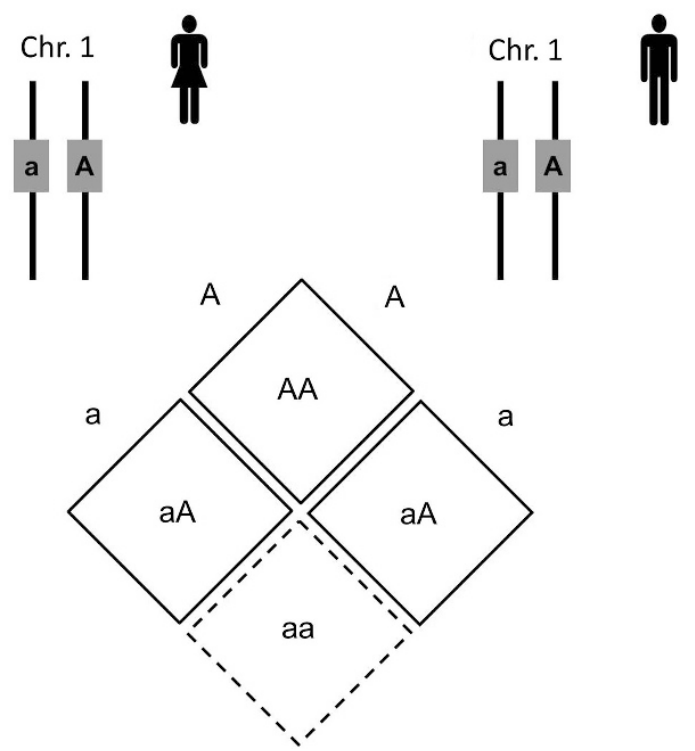

Figure 2 The recessive case is illustrated by two known alleles of a given locus, one recessive (a) and the other wild type (A). In this illustration, both parents are phenotypically unaffected, but carriers of the recessive gene. Meiotic division during gametogenesis produces oocytes and spermatozoa carrying either the recessive or the wild-type allele. The probability, $P$, of the genotypes in the offspring is given by $P=1 / 2 \times 1 / 2=1 / n^{2}=0.25$. Unaffected $(\mathrm{AA})$ and unaffected but carrier $(\mathrm{aA})$ make up $75 \%$ of embryos produced by the couple of heterozygous carriers of the recessive gene. The affected, recessive homozygous status (aa) is highlighted by the dashed square. Chr., chromosome.

heterozygosity. Inbreeding depression and heterosis imply that a substantial amount of polymorphisms including single-nucleotide polymorphisms, insertion or deletion polymorphisms, tandem repeats (short tandem repeats and variable number of tandem repeats), copy number variations (that is, duplications or deletions that change the copy number of a larger ( $>1 \mathrm{~kb}$ ) segment of a DNA sequence), ${ }^{57,58}$ regions of homozygosis ${ }^{59,60}$ and some rearrangements such as inversions and translocations (also known as copy-neutral variations) are deleterious. ${ }^{61-65}$ Accordingly, hybrid vigor is determined by functional rescue through nonmutually exclusive, genetically determined and environmentally modified mechanisms, including dominance complementation, overdominance and epistasis, ${ }^{66}$ and also intergenomic recombination and gene conversion; that is, recombination and gene conversion between alleles of different descent, or between the parental genomes. ${ }^{67-72}$

The hybrid vigor effect has been observed in a wide range of plant and animal species. In a sense, hybrid vigor can be regarded as an evolutionary driver of sex in a changing environment, for sexually reproducing individuals in outbreeding populations efficiently share genetic information, thereby increasing the adaptability of their offspring in a much more efficient way than asexually reproducing individuals, or sexually reproducing individuals in inbreeding populations.

Among astute plant and animal breeders, it is a long-standing realization that mating the most genetically distant parents usually produces the healthier offspring. Maximal hybrid vigor is obtained when different inbred populations are intercrossed to generate the socalled F1 generation. It is rather unlikely that the same harmful genes will be fixed in two different inbred lines; if we cross such lines, therefore, each can compensate for the deficiencies of the other, and 
the hybrid F1 stocks will be more vigorous than either of the two parental stocks from which they were derived.

Thus, in plant and animal stockbreeding, a conventional strategy to optimize hybrid vigor is to outbreed serially inbred populations. This is well illustrated in a study of inbred and outbred populations of a beetle species, Stator limbatus. ${ }^{73}$ In this study, the survival of outcrossed beetles evolved to be higher in the serially inbred populations. Also, inbreeding depression and the genetic load were significantly lower in the serially inbred than control populations. Inbreeding depression affecting larval survival of $S$. limbatus was largely because of recessive deleterious alleles of large effect that could be rapidly and extensively purged from the population by serial sibmating, specifically a reduction of as much as $72 \%$ could be attained in only three generations of sib-mating. The price for this astonishing success was the high rate of extinction of the inbred lines, despite the lines being reared in a benign laboratory environment, indicating that intentional purging of the genetic load of captive endangered species will not be practical because of high rates of subpopulation extinction.

In outbreeding populations like ours, the selection pressure acting on recessive alleles is relaxed, making harmful genes pile up across generations, until equilibrium or compromise is achieved between maximal adaptation (homozygosity) and maximal adaptability (genome-wide heterozygosity).

Consanguinity can theoretically increase the relative fitness of a population under specific ecological conditions, as illustrated in the $S$. limbatus inbreeding experiment as reviewed above, and a number of other plant and animal species, ${ }^{74}$ including some human populations in which consanguine marriages are widespread. ${ }^{75}$ The overall social benefits of consanguinity in our species — such as ease of marriage arrangements, greater compatibility with in-laws, the economic benefits of reduced dowry and the maintenance of any landholdings ${ }^{76}$-may sometimes outweigh genetic costs of inbreeding. However, intentional purging of the genetic load through inbreeding within human populations would be unethical and unfeasible. The human genetic system simply does not lend itself to improvement by selective inbreeding. As pointed out by Peter Medawar, 'we could not adapt modern stockbreeding principles to a human society without abandoning a large part of what we understand by being human. ${ }^{77,78}$

Clearly, the intention to purge harmful genes from our population is sensible, but some way other than inbreeding has yet to be devised, if we are serious about our intention to diminish human suffering caused by inherited diseases.

\section{Stretching the limits of heterosis in an outbreeding species}

In a population of diploid, sexually reproducing, outbreeding, polymorphic, unspecialized, altricial and cultural species like man, the deleterious mutants are only partly expressed in each generation, being largely concealed by heterozygosis with more favorable alleles. Although homozygosity for two or more deleterious genes with possibly synergistic effects is unlikely at the low levels of inbreeding found in humans, a substantial fraction of infant and juvenile deaths in nonconsanguine marriages may be attributed to heterozygous effects of the same factors that cause deaths as homozygotes in consanguine marriages. ${ }^{45}$

A review of a number of conditions for which relevant deviations in heterozygotes are possible or even likely included phenylketonuria (slight reduction of average-especially verbal-I.Q. in heterozygotes, together with signs of a slightly increased cerebral irritability, a possible slight increase of risk for mental disease and an increase of blood phenylalanine levels in stress situations), lipid storage diseases, microcephaly, myoclonus epilepsy, Wilson's disease, galactokinase deficiency, homocystinuria, recessive myotonia and ataxiateleangiectasia (increased cancer risk), among other diseases. ${ }^{79}$

Accordingly, one would expect an only limited effect of increasing genome-wide heterozygosity on the overall fitness or hybrid vigor in outbreeding human populations. A more pronounced effect is to be expected in the offspring of parents who descend from different populations that had remained reproductively isolated from each other for a long time. Individuals from different populations or subpopulations (demes) carry different profiles of rare and common variants, and low-frequency variants show substantial geographic differentiation that is further increased by the action of purifying selection. ${ }^{80}$ In practical terms, marriages between individuals from such diverse, 'differently inbred' demes would produce the kind of genome-wide heterozygosity that is expected to produce heterosis. This expectation has been confirmed as the human population structure moves from a historical metapopulation, comprising small and mainly rural endogamous communities, to large and panmitic urban populations. A genome-wide deleterious mutation with local differentiation favors dispersal-even though migration reduces average fitness-because migrant offspring have higher fitness than offspring of residents. ${ }^{81}$ This ongoing process is predicted to increase outbreeding and genome-wide heterozygosity, with beneficial effects on a range of traits associated with human health and disease. ${ }^{82-85}$

Within admixed populations, heterosis losses may result from 'incorrect matings', as observed in animal breeding schemes. ${ }^{86}$ In such populations, the problem of improving overall fitness through genome-wide heterozygosity can be solved by optimizing the genome-wide genetic distance of parents; as such, marriages would favor the recombination of advantageous alleles. Whereas the genetic distance between parents can be inferred from the history of families, pedigrees and ethnicities, molecular diagnosis is much more efficient in detecting genetic distance, identifying cryptic relatedness ${ }^{87}$ and scoring it according to risk. A valid marker-assisted optimization strategy might be to favor marriages between people with the least heterozygosities in common and the maximal reciprocally distinct homozygosities.

\section{The environment is a faithful guide to assortative mating}

Natural selection acts on the genetic structure of populations and species to increase adaptation to a given environment. Natural selection continues to operate in modern mankind, but its action ought to be supplemented by artificial selection ${ }^{88}$ and assortative mating. Assortative mating and its consequences for the offspring in our species have been classically studied at the phenotypic level, usually in connection with somatic, personality and cultural traits. ${ }^{15,89}$ Now it has become technically possible to direct mate choice based on cryptic gene variants known to confer adaptedness and fitness under more exacting environmental conditions. We have already discussed the case of increased fitness conferred by the sickle cell anemia trait when malaria is endemic. Another example of such advantageous gene variants is an As3MT (arsenic( + III)methyltransferase, the major arsenic-metabolizing enzyme) haplotype associated with reduced health risks due to rapid arsenic excretion and lower urinary fraction of the monomethylated metabolite. ${ }^{90}$ Natural selection for tolerance to the widespread environmental stressor arsenic may have increased the frequency of protective variants of As3MT in indigenous human populations exposed to this risk over historical time. ${ }^{91}$ The worldwide increase in natural and anthropogenic arsenic ${ }^{92,93}$ not only imposes the need for policies, regulations and actions to control or ban polluting activities, and reduce and monitor people's exposure to 
this ubiquitous, persistent environmental risk, but it also creates a demand for solving the problem of actively increasing the frequency of protective genetic variants in at-risk populations. Pairomics might solve this problem in different ways, as the arsenic-resistant phenotype is co-determined by genes other than As3MT that are located in different chromosomes. ${ }^{94}$

\section{GENETIC MARKERS IN PAIROMICS}

A genetic marker can be either a coding DNA sequence or gene or a noncoding DNA sequence with a known location on a chromosome so that it can be used to identify genes and clusters of genes, chromosomes and chromosome regions, individuals or species. We have mentioned previously that $\sim 1-2 \%$ of the DNA content of our genome corresponds to protein coding sequences. These regions undergo a tighter selection pressure against variation as compared with the vast majority of noncoding DNA sequences.

The so-called 'satellite sequences' (for example, short tandem repeats and variable number of tandem repeats) are noncoding regions of the genome that flank the coding regions or genes. Satellite sequences are subject to lower selection forces than are gene sequences, resulting in a higher mutation rate as compared with the coding sequences. Some advantages of using satellite sequencing instead of direct gene sequencing as genetic markers include their relatively low cost, widespread use (the use of satellite markers is widespread in current commercial paternity test kits) and 'neutrality' as it refers to the inability of satellite sequences to directly disclose a protein coding sequence.

The genome-wide sequencing of coding regions provides more accurate information on alleles linked to genetic diseases. The disadvantages of this approach include the relatively high cost, our incomplete knowledge of the meaning of sequence variation and the ethical, legal and social issues (ELSIs) involved in the disclosure of sensitive genetic information. It is expected that the spread of NGS and improvements in data analysis in genome-wide association studies will contribute to clarify some uncertainties pertaining to sequence variation, and reduce the cost disadvantage of whole genome sequencing. ${ }^{95,96}$ Still, there are potential ELSIs involved in the disclosure of whole genome genetic information. ${ }^{97}$ The social perception of risk moves from 'genetic display' to 'genetic striptease' as the type of genetic information moves from 'neutral' to 'specific'. It is thus understandable why neutral markers may be more acceptable in medical and recreational applications of pairomics such as mate choice.

The alleged disadvantage of neutral markers, namely the lack of specific information on the coding sequences, is also one of their advantages. Information derived from the use of neutral markers avoid stigmata such as 'carrier of a deleterious mutation', 'chromosomal aberration' and 'large-scale deletion' that often follow specific diagnoses. Therefore, an individual whose genome is undergoing screening for some serious genetic disease may also request that his or her carrier status not be disclosed to him or her, and it is ethically acceptable to honor such requests. ${ }^{98}$

In our typically outbreeding population, each one of us carries a large number of balanced deleterious alleles that are inherited from our parental germlines. A genome-wide screening with 'neutral' markers would yield 'neutral' results in virtually $100 \%$ of cases. However, a screening with specific markers would yield 'pathologic' results in essentially $100 \%$ of cases. Although it is hardly possible to purge some deleterious genes, this would be an utmost expensive, time consuming and ethically destitute enterprise, meaning that it is practically unfeasible.
The question remains as to whether neutral markers could substitute for disease markers in some medical applications of pairomics such as mate choice? Another question remains as to the alleged health and evolutionary perils of a change in the genetic structure of the population. We shall answer these questions in the following sections.

\section{Increasing heterozigosity with neutral markers}

It has been argued that the clinical management of sequence variations of unknown significance, including the consideration of abortion, makes genetic testing very difficult and ambivalent. ${ }^{99-101}$ However, sequence variation is the general principle underlying genetic distance, and heterosis as a function of genetic distance has withstood the test of time. Therefore, it appears to be enough reason to use variable regions as markers in premarital genetic counseling for mate choice based on increasing heterosis in the offspring.

From a simple algebraic viewpoint, it seems obvious that the higher the number of neutral and coding loci in the genome, the better the correlation between markers and genome heterozygosity. ${ }^{102}$ This general rule notwithstanding, there are reasons to believe that an analysis of a relatively small number of strategically positioned neutral markers can substitute for genome-wide gene sequencing in predicting heterozygosity. In the presence of gene interaction, natural selection tends to enhance the linkage intensity between genetic loci or maintain the same linkage relationship. ${ }^{103,104}$ In consequence, genomes have such a peculiar modular architecture that subsets of strongly epistatic mutations are tightly physically linked. 105

In addition, the interplay between sex and genetic architecture is such that it is possible that sex and recombination have affected their own evolution. ${ }^{106}$ Recombination rates through meiotic crossover (Figure 3) vary across the human genome, the majority of crossovers occurring in narrow hot spots inferred from linkage disequilibrium

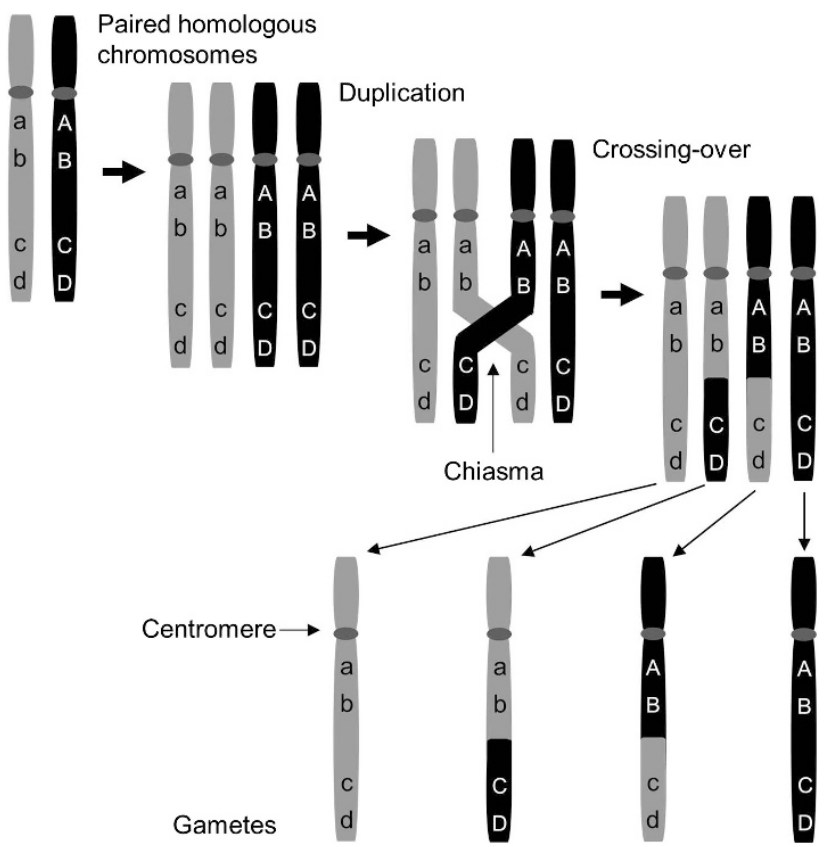

Figure 3 Genes are linked in clusters or modules within chromosomes. Crossover hot spots indicate that crossover events are nonrandomly distributed during meiotic recombination. Gene loci co-segregate in clusters (or in 'linkage'). Drawing adapted from: TH Morgan et al., 107 'The Mechanism of Mendelian Heredity', 1915. 
studies, with individual hot spots often active in both sexes. ${ }^{108-111}$ Important sources of variation in recombination hot and cold spots are the transposable elements. Some $40-50 \%$ of our genomes comprise transposable element copies. ${ }^{112}$ A large part of these elements is dormant, but a number of them are actively jumping in our genomes today and, in rare cases, these events cause mutations that lead to disease. ${ }^{113}$

The fact that alleles segregate and recombine in clusters or modules of loci separated by recombination hot spots makes it certain that genome-wide heterozygosity in the offspring is more reliably predicted at the recombination cluster level, than at the allele level. In consequence, any polymorphic marker that co-segregates with the cluster is informative for the constitution of an optimized parental pair out of a number of possible parental pairs, even if the marker is a noncoding sequence, also called an indirect or 'genetic-neutral' marker.

The effectiveness of using specific or neutral markers in pairomics might be determined by the degree of gene clustering within chromosomes. It may well be the case that specific information on a given locus in a given chromosome would be indicative for the formation of a given parental pair. However, this indication is diluted out in the myriad of possible combinations of other independent loci and gene clusters. As a result, the more markers taken, the more questions arose, the more time and other resources spent for the analysis and validation of the appropriate markers and marker combinations, without necessarily adding practical value to the assay.

The paradoxical situation is this. Our capability of predicting genome-wide heterozygosity in the offspring does not improve appreciably as a function of marker number within a given genomic module. However, our genome is large enough to allow predicting genome-wide heterozygosity with a relatively small number of neutral markers linked to recombination hot spots. It is therefore warranted to use a number of robust, neutral markers that have been shown to exhibit polymorphism within human populations and are located within gene clusters between recombination hot spots. Candidate neutral markers include pericentromeric regions and restriction fragment representations of individual genomic modules (Figure 4).

\section{THE EFFECTS OF MATE CHOICE THROUGH PAIROMICS ON THE GENETIC STRUCTURE OF HUMAN POPULATIONS}

The effects of mate choice with the help of pairomics on the genetic structure of human populations can be examined on the basis of the alleged threats of eugenics, such as the genetic manipulation for domination of mankind by some sort of tyrant, and the threat of genetic deterioration of mankind. It has been argued that schemes to mask deleterious alleles in a heterozygous condition could significantly increase the deleterious-allele frequencies while resulting in only a slight reduction in mortality in a population. ${ }^{114}$ It has been hypothesized that interdeme mating may lead to potentially harmful incongruences or incompatibilities among hardly won, nicely balanced adaptions. ${ }^{115,116}$ Let us examine these cases as follows.

\section{Can pairomics be eugenic or eugenomic?}

Pairomics is not to be confused with eugenics, a term coined by Francis Galton to define the genetic improvement of organisms, with special attention to the possible improvement of humans 'under the conditions of law and sentiment.' ${ }^{17}$ However, pairomics can be used as a tool in partner choice, assortative mating and assisted reproduction that have important functions to fulfill in human society.

A distinction has been made between eugenics or 'genetic improvement', and eugenomics or 'genome-wide improvement'.118

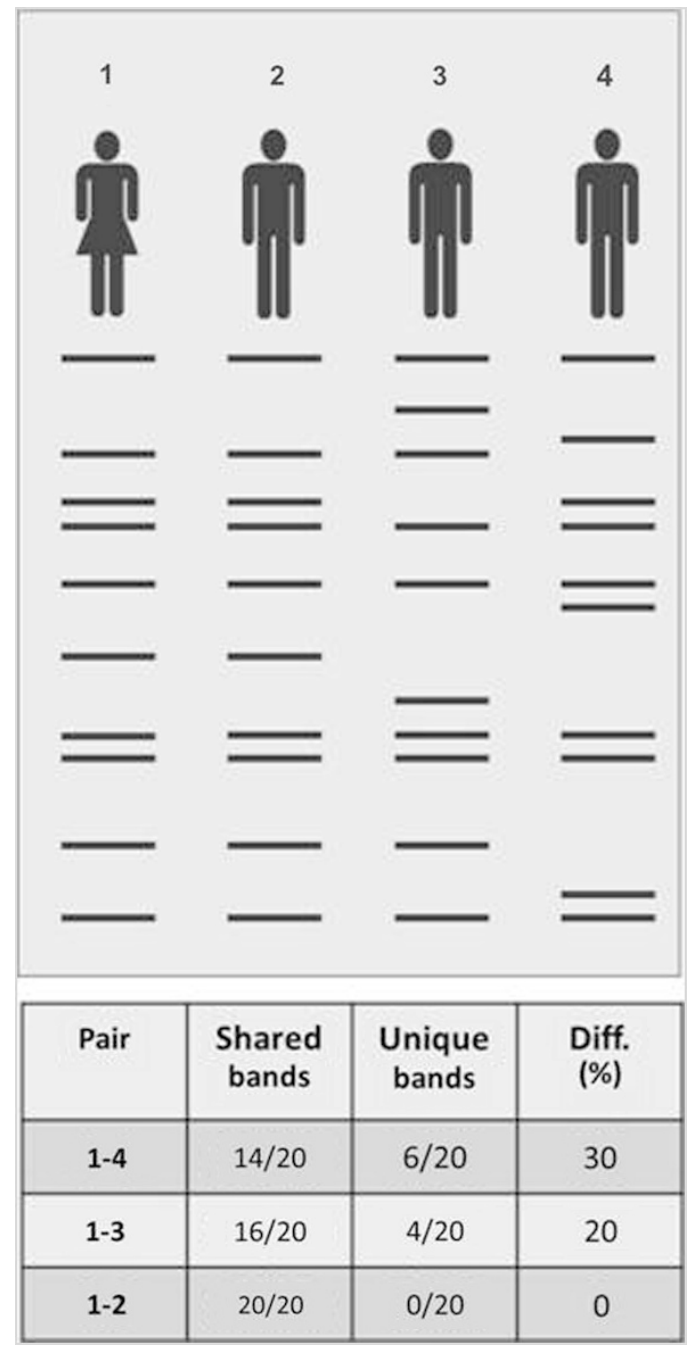

Figure 4 Amplified fragment length polymorphism (AFLP) analysis can be employed in a premarital counseling model for increased genome-wide heterozygosity in the offspring. Couples are depicted by decreasing intergenomic difference (Diff. (\%)) hinting at decreasing odds of hybrid vigor in the respective offspring.

The difference between eugenics and eugenomics is not of principle, but of degree. Both presuppose some degree of inbreeding and homozygosis, for only homozygous individuals can breed true. Whereas homozygosis is common for a number of genes in plant and animal populations, genome-wide homozygosis has not been reported so far in human populations. Inbreeding depression in a hypothetical human population undergoing a eugenomics program would be so extremely wasteful that any form of human eugenomics can be forecast to be highly unlikely, if not impossible, to occur in our species.

In addition, pairomics as an eugenic expedient would be extremely less efficient than artificial insemination and, yet, in a review on artificial insemination by selected donors as an eugenic expedient, Richards ${ }^{119}$ noticed that artificial insemination by selected donors found very little favor with those who might use it, not least because of the fact that a couple's desire to have their 'own' children has always seemed stronger than any eugenic aspirations. Also, he notes, no state has ever contemplated using artificial insemination by selected donors as a social policy. 
Other authors have made the distinction between state eugenics and eugenics as an individual choice, ${ }^{120}$ or recommended that reproductive decisions should not be made primarily on the basis of social cost. ${ }^{121}$ Any restriction on using assisted reproduction techniques such as pairomics, IVF and preimplantation genetic diagnosis (PGD) to prevent the birth of children affected by genetically transmissible conditions would breach national and international Conventions on Human Rights. Assisted reproduction is a human right, and individuals should not face illogical and discriminatory restrictions to their right to private and family life. ${ }^{122}$

\section{Fostering genome-wide heterozygosis has negligible effects on the genetic structure of mankind}

The alleged threats of schemes to mask deleterious alleles in a heterozygous condition do not apply to a diploid, sexually reproducing, outbreeding, polymorphic, unspecialized, altricial and cultural species such as ours. It can be said, from the viewpoint of genetic evolution, that our species has retained an 'amateur status.' ${ }^{123}$ Natural selection forces that act upon our genomes to eliminate harmful genes tend to be attenuated by our capacity to change our environment through improvements in nutrition, housing, hygiene, education, lifestyle and medicine. As a result of this status quo, a number of unselected deleterious genes already tend to pile up in the heterozygous state in human populations.

In addition, there is evidence that our genetic system cares for the maintenance of genome-wide heterozygosis. This is illustrated by the studies on major histocompatibility complex and mate choice carried out by Wedekind et al. ${ }^{124,125}$ The research team asked men and women to score the odors of T-shirts worn by women and men. Their scorings of pleasantness correlated negatively with the degree of major histocompatibility complex similarity between the individual smelling and the T-shirt wearer in men and women. This suggests that the major histocompatibility complex or linked genes influence human mate choice today, and the observed preferences would increase heterozygosity in the progeny.

\section{Genome-wide heterozygosis may protect against a number of diseases}

A number of studies have confirmed the heterotic advantage in other loci related to host resistance to infectious diseases. ${ }^{126,127}$ In a review on facial aesthetics and attractiveness in man, Edler and Orth ${ }^{128}$ pointed that 'human perception of attractiveness is firmly anchored in evolutionary biology, in that it is an essentially sexual characteristic, based on the need to find the most suitable mate for the production of healthy offspring. These authors reviewed evidence that a great deal of attractiveness is based on parasite resistance, and concluded that parasite resistance is enhanced by heterozygosity, which in turn is 'advertised' by averageness in body proportions-particularly, in humans, in the female. The authors did not provide any genetic explanation for gender differences, although the presence of a single copy of the $\mathrm{X}$ chromosome in males may result in increased exposure to recessive deleterious genes, suggesting a mechanism for increased male frailty ${ }^{129}$ that presumably operates a negative male selection mechanism.

In a study of malocclusion in an ethnically admixed population, the ethnicity effects were found to be largely additive, and no significant effect of hybridity of child or recombination was found, indicating that intercrosses, or crosses between individuals from genetically distant human demes, present no additional risks for malocclusion in the offspring. ${ }^{130}$
Other positive effects of genome-wide heterozygosity on a range of biomedically relevant human quantitative traits have already been reviewed above. It is worthwhile stressing the role of heterozygosity in preventing cancer development. Indeed, loss of heterozygosity-a genetic mechanism by which a heterozygous somatic cell becomes either homozygous or hemizygous because the corresponding wildtype allele is lost-has been recognized as a major cause of malignant growth. ${ }^{131}$ Monoallelism on a genome-wide scale, a seminal feature of cancers, is a general fitness liability. ${ }^{132}$

Thus, there is no reason to believe that maintaining or even increasing the frequency of heterozygotes in the offspring of our already outbreeding human populations would result in any major change or biologically evil effect on the genetic structure or average well-being of mankind. On the contrary, there is every reason to believe that heterozygosis is constitutive for our species because it results in more adapted genotypes, and any scheme aimed at maintaining or increasing heterozygosis in the offspring would not appreciably change the genetic structure of our outbreeding population, but would increase average adaptability and well-being.

Assortative mating is widespread in human reproduction schemes It is in principle true that genetic assistance in assortative mating can significantly alter the genetic structure of a given population. Per definition, assortative mating or nonrandom mating causes abnormalities regarding the frequencies that would be expected according to the Hardy-Weinberg principle. The Hardy-Weinberg principle states that both allele and genotype frequencies in a population remain constant from generation to generation unless specific disturbing influences are introduced. Those disturbing influences include not only assortative mating, but also mutation, selection, random genetic drift, gene flow and meiotic drive. ${ }^{133}$

Assortative mating is widespread in the reproduction schemes of sexually reproducing species, including man, and it is directed by as yet poorly understood genetic and nongenetic mechanisms. ${ }^{134,135}$ Assortative mating has an evolutionary meaning, as it works in concert with natural selection to achieve local adaptations and reproductive isolation, even in the presence of substantial gene flow. ${ }^{136}$ The model of incompatibility of genes between two isolated populations to explain reproductive isolation through hybrid inviability ${ }^{137}$ is controversial, although it appears applicable to the evolution of cis-regulatory elements and transcription factors. However, there is no evidence for such things as reproductive isolation or hybrid inviability within the human species. On the contrary, human genetic diversity provides for unlimited assortative mating. Harpending and Cochran ${ }^{138}$ distinguish the consequences of genetic diversity for fitness, relevant to evolution, from the consequences for well-being, relevant to medicine and public health. They call genetic variation that causes impairment of health or well-being of individual humans 'apparent genetic burden' and a variation that has effects on fitness but not well-being 'unapparent genetic burden'. They also distinguish between adapted genes and adapted genotypes: 'an adapted gene is a gene that increases the fitness of its bearer either in a heterozygous or a homozygous state or both, while an adapted genotype is a genotype that increases the fitness of its bearer but is not transmitted intact to future generations. Balanced polymorphisms in which the heterozygote is superior in fitness may generate most adapted genotypes. In the face of major rapid environmental change, adapted genotypes appear first but over time they are replaced by adapted genes.'

Accordingly, it has been demonstrated that whenever heterozygotes are less fit, on average, than homozygotes at the trait locus, indirect 
selection for assortative mating is generated. ${ }^{139}$ Thus, assortative mating through genetic assistance is not essentially different from a natural scheme. However, an important difference between natural and genetically assisted assortative mating does exist. The natural scheme is operated through natural selection, meaning that any decline in fitness precedes natural assortative mating, whereas genetically assisted assortative mating prevents the decline in fitness from known deleterious alleles or genotypes. The conclusion that can be drawn from this difference is surely this: genetically assisted assortative mating is a more humane solution, as it prevents human suffering.

A pairomics-assisted mate choice using a combination of neutral markers (for example, variable number of tandem repeats and short tandem repeats) and gene-specific markers (for example, singlenucleotide polymorphisms have been widely used to study polymorphism because they are widespread across the whole of the genome and offer a higher resolution compared with other markers) may help to maintain a beneficial overall heterozygosis, while increasing the frequency of certain beneficial alleles, respectively, in the offspring. An optional preimplantation diagnosis may help to purge some known deleterious alleles, and further enhance our capacity to reduce the risk of known genetic diseases in the offspring.

The perils of fixation of novel mutations with unknown effects are negligible. If one considers the present size of the human population ( $\sim 7$ billion), with a mutation rate of $\sim 2 \times 10^{-8}$ per base pair per generation, then every site in the genome compatible with survival has mutated an average of 280 times in just the most recent generations. However, most of these base substitutions are rare in human populations. Recent estimates predict that $>15$ million single-nucleotide polymorphisms with minor allele frequencies exceeding $1 \%$, and $>7$ million single-nucleotide polymorphisms with minor allele frequencies exceeding $5 \%$, will be found in the human genome. ${ }^{140}$

\section{EFFECT OF POPULATION SIZE ON THE OUTCOME OF PAIROMICS}

Earlier, we discussed the fact that gene loci segregate and recombine in linkage; that is, as clusters or modules generally constrained by hot spots. Recombination events increase in number as a function of genetic diversity and generation number (recombination occurs during meiosis in each generation). As pointed out by Keightley and Otto: ${ }^{141}$

'Background selection against deleterious mutant alleles provides a stochastic advantage to sex and recombination that increases with population size. Sex and recombination reveal the hidden genetic variance in fitness by combining chromosomes of intermediate fitness to create chromosomes that are relatively free of (or are loaded with) deleterious mutations'.

In the recessive case, a 'dominant' allele from one parent suffices to counterbalance the effect of the deleterious mutant allele from the other parent. This beneficial effect increases with population size (Figure 5).

An infinitely large population size is an assumption underlying the Hardy-Weinberg equilibrium, and it is also a safeguard against widespread deleterious recessiveness. As the overall recessiveness in the offspring is inversely related to population size, then the difference between parental allele pairs in each of a number of loci-in a word, the genome-wide heterozygosity or diversity — can be optimized by increasing the number of participants from diverse populations in a pairomics database: 'the more options, the more hits'.
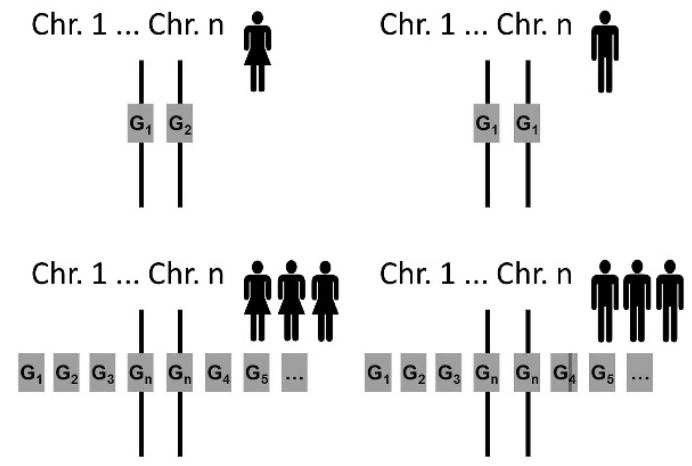

Figure 5 The larger the population size, the higher the probability of heterozygosity at a given gene locus, G. Chr., chromosome.

\section{ETHICAL, LEGAL AND SOCIAL ISSUES}

Pairomics may introduce some original, novel ethic concerns as compared with existing techniques of assisted reproduction such as AI/IVF and PID/PND. Therefore, we highlight major differences between pairomics and those existing techniques as follows.

In AI/IVF or PID/PND, a decision is made by an already formed couple as to whether an embryo or fetus should be artificially generated, implanted, treated or aborted based on its genetic constitution, among other nongenetic criteria. AI/IVF and PID/ PND are usually employed to overcome an acquired sterility or a monogenetic disease affecting the reproductive capacity or fitness of an already formed couple.

In pairomics, it is the partners who deliberately choose each other to form a couple, based on their mutual genetic compatibility, among other nongenetic criteria. Thus, the focus of pairomics lies in assisting an individual in his or her process of searching for a partner with the help of a comprehensive, genome-wide analysis, in addition to the individual's own search criteria.

Although pairomics can help to decrease the prevalence of inherited diseases in the offspring, this is not the sole criterion of a mate search performed with the help of pairomics. Other search criteria such as age, ethnicity, culture and education are always involved in a mate search.

For the above reasons, pairomics as a technique of assisted reproduction can be regarded as both preventative and recreative, whereas AI/IVF and PID/PND are more 'remedial' in nature. As the decision-making process in pairomics is directed toward adult individuals, not toward gametes or embryos as in AI/IVF and PID/ $\mathrm{PND}$, there is the concern that people might be discriminated for or against, depending on the pairomics criteria used for partner choice. Because of a general increase in genetic testing, carriers of alleles for some severe disease could face stigmatization or discrimination, whereas carriers of some 'desirable' or 'normal' traits could be favored. The opposite situation, namely the masking of an acquired disease or an undesirable phenotypic trait through a 'blind' pairomics partner choice process, may also occur.

Therefore, the criteria and principles applied to mate choice with the help of pairomics should be developed and presented in a form that is clearly understandable for the general public, scientifically validated and ethically and socially acceptable. Most importantly, pairomics should and will not be used as the sole cue in partner choice.

\section{Mutual disclosure of genetic information}

Another ethical concern introduced by pairomics is the mutual disclosure of genetic information of people using pairomics tools to 
find a matching partner. 'Matching' here presupposes some form of complementarity between two individual genomes. To appreciate the degree or nature of the complementarity, the individuals in a putative pair may like to have access to detailed information on each other's genetic makeup. This type of mutual disclosure of genetic information is potentially harmful to the individuals involved, and should therefore be protected by anonymization or pseudonymization. Alternatively, genetic information of the 'neutral type' should be used.

\section{Public awareness and acceptance of genetic information}

In the foreseeable future, many millions of people around the world will have access to the complete sequence of their own genomes. The massive increase in individual genomic information may not be accompanied by a sufficient increase in genetic counseling capacity or social understanding of the potential and limitations of this information. ${ }^{142}$ The potential of genetic information to influence life planning, behavior and culture is overwhelming.

However, even modern societies need time to tap into this potential, as is the case for example in information technology. The perception of scientific progress follows only partly rational considerations, for it is characterized by the interplay of biological, health, psychological, emotional, financial, religious, ethical, legal and social aspects. These aspects of human life and psychology also permeate public perception of genetics; for example, the question of whether to eat genetically modified organisms or not.

People tend to accept scientific solutions to any problem if some immediate hazard or damage is involved. Solutions are less easily appreciated, and therefore less easily accepted if mediated hazard or damage is involved; for example, preventative interventions to avoid health problems. As in any field of science, acceptance of genetic testing is more likely to occur if scientific knowledge is organized in such a way as to produce immediate, sensitive, pleasant, useful or helpful solutions. Through a quantitative and qualitative analysis of the web sites offering direct-to-consumer (DTC) genetic testing through Internet, it seems that companies target a triple market based on: (1) the 'healthism' that raises health and hygiene to the top of the social values; (2) the contemporary demands of the users to become actors of health decisions; and (3) the need for biosocial relationships. ${ }^{143}$

Of great importance in the future could be to find or choose mates who would constitute a 'perfect pair'. The sociodemographic change has led to lowering of birth rates and increasing of life expectancy. The declining number of children, the increasing living costs and the high rate of separation and divorce strengthen the desire for healthy offspring and a fulfilling and harmonious life. The psychological as well as economic impacts of genetic diseases and disabilities of offspring on families and the community are a major source of concern. This situation naturally raises the question of the role that genetic information could play in individual mate choice and family planning.

The analytical methods are now so far advanced that a full analysis of the gene sequences is feasible and financially viable at the individual level. In addition to the study of fundamental mechanisms of function and regulation of genes, the characterization of the human genome, especially the identification of causes of diseases and new treatment approaches, are among the aims of modern human and medical genetics.

The search for 'polygenic' factors for common, multifactorial 'diseases of civilization' is a major focus of research. Whereas it is possible to identify some of the common gene variants with isolated, low predictive value and low penetrance, the applicability of the results for risk prediction remains limited. ${ }^{144}$ One reason for this is that the prevalence of the incriminated variants in the general population is high, i.e. the majority of the populations studied have a 'medium' risk. Genetic loci so far identified for complex traits account for only a small fraction of the overall heritability. In addition, a significant proportion of the 'missing heritability' of common diseases may be attributable to low-frequency variants with intermediate penetrance effects (Figure 6).

Another important, although less well documented, reason is the fact that the environment determines the risk associated with mostif not all-gene variants (Figure 1). Improvements in the environment or euphenics ${ }^{145}$ (for example, improvements in nutrition, housing, education, hygiene, lifestyle and medicine) can eventually lead to the disappearance of some harmful genes over generational time, as has been so nicely illustrated by the case of sickle cell anemia decline after malaria was stamped out. ${ }^{146-148}$ In many instances, however, questionable improvements have been shown to cause disease and reduce fitness, as when carriers of a thrifty genotype are exposed to ad libitum food intake. ${ }^{149-151}$ Such gene-environment interactions must be borne in mind in any genetic analysis and counseling. It is expected that gene-environment-wide interaction studies ('GEWIS') will help to understand the gene-environment interactions. $^{152}$

Far less well documented are approaches referring to genetic characteristics of postulated relevance for mate choice, although they are already being pursued commercially. In addition, genetically determined characteristics with no apparent clinical significance for medical research such as height, physique and behavior are in increasing demand for development and commercialization. Part of this development is characterized by substantial disregard of exogenous factors and sociocultural factors on the expression of the genetic 'normal variants'.

The need for a reappraisal of the medical, scientific, ethical and legal framework of omics applications follows from the observation that this type of service is already being advertised and offered by commercial organizations on the Internet and in the lay press. A great deal of these services is run on a DTC basis, thus bypassing medical and psychological counseling services, with foreseeable medical and psychological consequences for the consumer.

Whereas the genetics of monogenic traits is easier for people to understand, the genetics of polygenic traits may be too complicated or ambivalent. For example, it is easy to understand that homozygosity for a known missense mutation of the phenylalanine hydroxylase $(P A H)$ gene and normal levels of phenylalanine in the diet are sufficient to cause phenylketonuria and severe mental retardation in

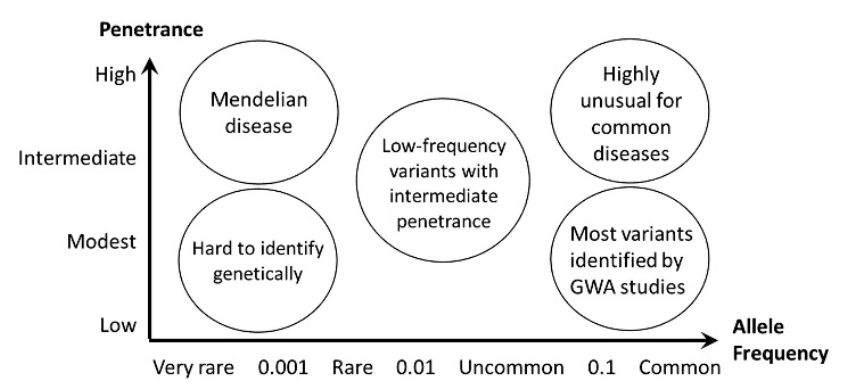

Figure 6 Low-frequency variants and disease susceptibility. A significant proportion of the 'missing heritability' of common diseases may be attributable to low-frequency variants with intermediate penetrance effects. GWA studies, genome-wide association studies. Adapted from McCarthy et al. ${ }^{167}$ 
newborns. Comprehensive genomic information is so much more complicated that we are not able to understand it without some kind of computational genomic tool, scientific evidence or professional assistance.

However, neither medical and scientific validity nor legality and ethical issues appear to be clarified as yet. In 2010, the European Society of Human Genetics (ESHG) stated that 'DTC genetic testing and the advertisement of genetic tests of unproven benefit or without adequate independent genetic counseling are in opposition to the professional standards the ESHG sustains. ${ }^{153}$

\section{Reasons for and against genetic diagnosis}

People may seek genetic diagnosis and counseling (GDC) at different life times. Preconception genetic diagnosis and counseling (PreCGDC) may occur after a couple is formed with the intention of having an offspring, or even before a couple is formed, in which case PreCGDC may be sought as a cue to mate choice.

Postconception genetic diagnosis and counseling (PostC-GDC) can be distinguished according to the time points after conception: preimplantation (PreI-GDC), prenatal (PreN-GDC) and postnatal genetic diagnosis and counseling (PostN-GDC).

In 2008, the Practice Committee of the American Society for Reproductive Medicine (ASRM) recommended PGD with IVF as a significant advance over postconception diagnosis and pregnancy termination in the case of single-gene disorders. ${ }^{154}$ It noted, however, that long-term consequences for the offspring after PGD cannot be ruled out with certainty at present. With the available PGD technology, moreover, testing is only available for single-gene diseases, and risks of diagnostic error remain. ${ }^{155}$

In 2013, the Ethics Committee of ASRM considered PGD for adultonset conditions ethically justifiable when the conditions to be avoided are serious and when there are no known interventions for the conditions or the available interventions are either inadequately effective or significantly burdensome. For conditions that are less serious or of lower penetrance, the ASRM considered PGD ethically acceptable as a matter of reproductive liberty. It should be discouraged, however, if the risks of PGD are found to be more than merely speculative. $^{98}$

Arguments offered in support of PGD for serious adult-onset conditions include the right to reproductive choice on the part of individuals who seek to bear children, the medical good of preventing the transmission of genetic disorders and potential social benefits of reducing the overall burden of disease. Arguments advanced against the use of PGD include expense, the questionable value of the medical benefits obtained in the light of our inability to predict medical progress over the longer term, the possibility of misdiagnosis and the unknown risks of the procedure. Critics have argued that this recommendation against testing fails to understand autonomy and to appreciate the harms that may be associated with uncertainty, ${ }^{156}$ but the recommendation was reaffirmed in 2009. ${ }^{157}$ In summary, the goal of preventing disease supports the liberty to use GDC, provided that the risks of GDC are not found to be more than merely speculative. Cost reasons also support the reproductive liberty to choose GDC. This is particularly relevant given the growing lifetime cost of health care for chronic medical conditions and the psychological impact of these diseases.

Ethical reasons on the other side of the argument include the possibility of misdiagnosis for technical reasons, uncertainties regarding medical benefits of GDC in view of variable gene expressivity and complex interactions between DNA and the environment. Other critics put forth the so-called 'designer baby' concern. ${ }^{158}$
The ASRM Committee further concluded that 'reproductive liberty arguments ethically allow for PGD for adult-onset conditions of lesser severity or penetrance. In the latter cases, the application of the technology hinges on the evidence that PGD is a relatively low-risk procedure; this evidence may change. The complexity of the scientific, psychological, and social issues involved in this arena compels the Committee to strongly recommend that an experienced genetic counselor play a major role in counseling patients considering such procedures. ${ }^{98}$

The ELSIs of tests to verify the compatibility of potential mates have not yet been discussed in the current literature. The existing market suggests high growth rates. There is an urgent need to name and clarify the ELSIs of tests, building on current and future medical research. Consideration of test characteristics is essential to any valuable discourse on the ELSIs of personal genome testing. Four key characteristics of personal genome testing for multifactorial diseases-(1) targeted/nontargeted testing, (2) analytical validity, (3) clinical validity and (4) clinical utility-together determine the applicability and the relevance of ELSIs to specific tests. ${ }^{159}$ It is expected that medical research will show the currently existing medical limitations and the expected future developments. This will enable legislators to find correspondingly long-term legal solutions, with due regard to ethical concerns.

\section{Genetic assistance in reproduction as a universal human right}

It has been argued elsewhere that genomic medicine asks for universal coverage. ${ }^{160}$ Since public interest in genetic assistance in reproduction is featured in the global human population, and human beings are defined as intelligent animals, then there must be a universal right to genetic assistance in reproduction as well. It follows in consequence that: (1) clients and service providers alike must abide by the constitution and the laws of the country where they live or are established; and (2) cultural advancement is allowed, as the declaration of a natural right constitutes the basis upon which future permissive legislation will be constructed, and furthermore, prohibitive legislation will be abolished.

As any natural right, the right to genetic assistance in reproduction is part of the chain of natural causality: LIFE $\rightarrow$ SURVIVAL $\rightarrow$ CONTINUITY. Juridical causality runs in parallel and congruent with natural causality. A debate on strict juridical terms would be endless; a juridical paper inconclusive, whereas the natural causality approach remains irrefutable, for nobody dares to deny his or her own natural existence. Natural causality runs in parallel with intelligent causality because both belong to the real world. The natural right approach to genetic assistance in reproduction facilitates the understanding of the right to genetic assistance in reproduction, and serves the search for new rights or new practices of rights that are not codified in laws.

Universal coverage of genetic assistance in reproduction means that access to this technology becomes more important. Health outcomes may improve for those who can afford the technology, for example, but not for others. Without such access, technological innovation will likely expand disparities rather than reduce them and, hence, as efficacy of the technology grows, so does the burden on society to provide access to technology equitably to all those in need. ${ }^{161}$

\section{Genetic assistance in reproduction from the viewpoint of clients,} assistants and counselors

The scope of genetic assistance in reproduction is to provide supportive genetic information in informed reproductive decisions. An individual's needs ought to be the focus of genetic assistance in 
reproduction. Privacy has been the key term of bioethical debates on biobanks. However, the notion of control and controllability over collected personal data are most essential for people in the information society. ${ }^{162}$ Accordingly, providers of genomic information should allow people to select which types of risk information will be included in their report. ${ }^{163}$

As providers of information, medical assistants are protected from religious, ethical and philosophical issues. The very nature of assistance avoids the construction of persuasive medical arguments and facilitates referral within the realms of multidisciplinarity where clients are referred to their trusted assistants and counselors.

Personal contact with a counselor is limited to those cases where diagnosis cannot be made by document examination alone, opening the field to remote assistance (remote assistance includes visual contact via web conference to satisfy the need to 'see the face of the doctor') and outsourced personal contact. In this model, the emotional field is left open to those who are interested in it.

There are some risks in the 'help to make decisions' model. Assistants can provide clients with studies, statistics, doctrines and medical jurisprudence. However, assistants should not help clients to make their decisions, unless the assistant is the individual involved in affecting the reproductive decision (for example, reproduction scientists, geneticists). Ideally, genetic assistance in reproduction should be framed within a scientific nucleus (for example, universities and institutes), and maintained apart from the commercialoperational nucleus (for example, physicians, hospitals and companies).

Critical factors for genetic assistance in reproduction include: (1) compliance with national and international codes of ethics, (2) scientific validity, safety and utility of the gene tests used by the industry, (3) transparency, (4) community participation, (5) universal affordability, (6) quality of service and standardization to ensure that tests from different laboratories provide comparable results, (7) qualification and integrity of professionals and institutions involved and (8) computational power and -architecture that are commensurable with the needs of large, interactive and secure databases.

\section{CONCLUSION}

The human species is a diploid, sexually reproducing, outbreeding, polymorphic, unspecialized, altricial and cultural species. Humans are metagenomic with respect to the humans around them, ${ }^{164}$ and mate choice criteria that vary extensively among genders, people and cultures are firmly anchored in genomics. Furthermore, mate choice is a critical determinant of health and well-being. Thus, the development of the science and technology of pairomics is warranted.

As knowledge is expected to be generated in the process of developing pairomics at negligible risk, we should not refrain from developing the field, for fear of being wrong: 'In fussing over the nature of some great metamorphosis which might conceivably happen, but which could only happen in real life if we were to be the victims of a sustained and consistent tyranny tens of centuries long, we may forget to ask a really important question: what changes are happening in the genetic structure of human populations as a result of forces acting upon us now?'165

Understanding these forces and predicting their effects will not be an easy enterprise. Human genomic variation and the complexity of gene-gene and gene-environment interactions make sure that pairomics will be one of the most complex and challenging omics applications in the years to come. But in the words of Neil Pearce, 'If complexity is the price of being relevant and addressing the major public health problems, then so be it. ${ }^{166}$
As public knowledge on genomics, population genetics and geneenvironment interactions, as well as the size of genomic databases expand, so does the ability of pairomics to investigate and predict the consequences of mating preferences for present and future generations.

\section{CONFLICT OF INTEREST}

The authors declare no conflict of interest.

\section{ACKNOWLEDGEMENTS}

We thank J Taupitz, M Bobbert, P Bauer and O Riess for valuable discussions and $\mathrm{C}$ Maelicke for reading the manuscript.

1 Cavalier-Smith, T. Origins of the machinery of recombination and sex. Heredity $\mathbf{8 8}$, 125-141 (2002).

2 Cavalier-Smith, T. Origin of the cell nucleus, mitosis and sex: roles of intracellular coevolution. Biol. Direct. 4, 7 (2010).

3 Charlesworth, B. Mutation-selection balance and the evolutionary advantage of sex and recombination. Genet. Res. 55, 199-221, Republished in Genet. Res. 89, 451-473 (2007) (1990).

4 Kleiman, M. \& Tannenbaum, E. Diploidy and the selective advantage for sexual reproduction in unicellular organisms. Theory. Biosci. 128, 249-285 (2009).

5 Gavrilets, S. Human origins and the transition from promiscuity to pair-bonding. Proc. Natl Acad. Sci. USA 109, 9923-9928 (2012).

6 Weisfeld, G. E. \& Weisfeld, C. C. Marriage: an evolutionary perspective. Neuro. Endocrinol. Lett. 23 (suppl. 4), 47-54 (2002).

7 Maccoby, E. E. Different reproductive strategies in males and females. Child. Dev. 62, 676-681, discussion 682-5 (1991).

8 Skuse, D. H. \& Gallagher, L. Genetic influences on social cognition. Pediat. Res. 69 (5 Pt 2), 85R-91R (2011).

9 Epstein, E. \& Guttman, R. Mate selection in man: evidence, theory, and outcome. Soc. Biol. 31, 243-278 (1984).

10 Ben Hamida, S., Mineka, S. \& Bailey, J. M. Sex differences in perceived controllability of mate value: an evolutionary perspective. J. Pers. Soc. Psychol. 75, 953-966 (1998).

11 Fisher, H. E., Aron, A. \& Brown, L. L. Romantic love: a mammalian brain system for mate choice. Philos. Trans. R. Soc. Lond. B Biol. Sci. 361, 2173-2186 (2006).

12 Todd, P. M., Penke, L., Fasolo, B. \& Lenton, A. P. Different cognitive processes underlie human mate choices and mate preferences. Proc. Natl Acad. Sci. USA. 104, 15011-15016 (2007).

13 Roberts, S. C. \& Little, A. C. Good genes, complementary genes and human mate preferences. Genetica 134, 31-43 (2008).

14 Burrell, A. S. \& Disotell, T. R. Panmixia postponed: ancestry-related assortative mating in contemporary human populations. Genome. Biol. 10, 245 (2009).

15 Zietsch, B. P., Verweij, K. J., Heath, A. C. \& Martin, N. G. Variation in human mate choice: simultaneously investigating heritability, parental influence, sexual imprinting, and assortative mating. Am. Nat. 177, 605-616 (2011).

16 Candolin, U. The use of multiple cues in mate choice. Biol. Rev. Camb. Philos. Soc. 78, 575-595 (2003).

17 Sloman, L. The role of attractiveness and mate selection in phylogenetic adaptation with particular reference to early man. Biol. Psychiatry 12, 487-494 (1977).

18 Miller, G. F. The Mating Mind: How Sexual Choice Shaped the Evolution of Human Nature (Doubleday, New York, 2000).

19 Geary, D. C., Vigil, J. \& Byrd-Craven, J. Evolution of human mate choice. J. Sex. Res. 41, 27-42 (2004).

20 Haber, M., Gauguier, D., Youhanna, S., Patterson, N., Moorjani, P., Botigué, L. R. et al. Genome-wide diversity in the levant reveals recent structuring by culture. PLoS. Genet. 9, e1003316 (2013).

21 Boyd, R. \& Richerson, P. J. Culture and the Evolutionary Process (University of Chicago Press, Chicago, IL, 1985).

22 Laland, K. N., Kumm, J. \& Feldman, M. W. Gene-culture coevolutionary theory - a test-case. Curr. Anthropol. 36, 131-156 (1995).

23 Henrich, J. \& McElreath, R. in Oxford Handbook of Evolutionary Psychology (eds Dunbar, R. \& Barrett, L.) 555-570 (Oxford University Press, Oxford, 2007).

24 Oberzaucher, E. \& Grammer, K. Ageing, mate preferences and sexuality: a minireview. Gerontology 55, 371-378 (2009).

25 De Meyer, T., Rietzschel, E. R., De Buyzere, M. L., De Bacquer, D., Van Criekinge, W., De Backer, G. G. et al. Asklepios investigators. Paternal age at birth is an important determinant of offspring telomere length. Hum. Mol. Genet. 16, 3097-3102 (2007).

26 Kimura, M., Cherkas, L. F., Kato, B. S., Demissie, S., Hjelmborg, J. B., Brimacombe, $M$. et al. Offspring's leukocyte telomere length, paternal age, and telomere elongation in sperm. PLoS. Genet. 4, e37 (2008).

27 Eisenberg, D. T., Hayes, M. G. \& Kuzawa, C. W. Delayed paternal age of reproduction in humans is associated with longer telomeres across two generations of descendants. Proc. Natl Acad. Sci. USA 109, 10251-10256 (2012). 
28 Heidinger, B. J., Blount, J. D., Boner, W., Griffiths, K., Metcalfe, N. B. \& Monaghan P. Telomere length in early life predicts lifespan. Proc. Natl Acad. Sci. USA 109, 1743-1748 (2012)

29 Gillespie, D. O., Lahdenperä, M., Russell, A. F. \& Lummaa, V. Pair-bonding modifies the age-specific intensities of natural selection on human female fecundity. Am. Nat 176, 159-169 (2010).

30 Robinson, J., Waller, M. J., Parham, P., Bodmer, J. G. \& Marsh, S. G. IMGT/HLA Database-a sequence database for the human major histocompatibility complex. Nucleic Acids Res. 29, 210-213 (2001).

31 Spellman, S., Setterholm, M., Maiers, M., Noreen, H., Oudshoorn, M., FernandezViña, M. et al. Advances in the selection of HLA-compatible donors: refinements in HLA typing and matching over the first 20 years of the National Marrow Dono Program Registry. Biol. Blood. Marrow. Transplant. 14 (9 Suppl), 37-44 (2008).

32 Ferrari, P., Fidler, S., Wright, J., Woodroffe, C., Slater, P., Van Althuis-Jones, A. et al. Virtual crossmatch approach to maximize matching in paired kidney donation. Am. J. Transplant. 11, 272-278 (2011).

33 Bochtler, W., Maiers, M., Bakker, J. N., Oudshoorn, M., Marsh, S. G., Baier, D. et al. World Marrow Donor Association framework for the implementation of HLA matching programs in hematopoietic stem cell donor registries and cord blood banks. Bone Marrow Transplant. 46, 338-343 (2011).

34 Tachibana, M., Sparman, M., Sritanaudomchai, H., Ma, H., Clepper, L., Woodward, J. et al. Mitochondrial gene replacement in primate offspring and embryonic stem cells. Nature 461, 367-372 (2009).

35 Tachibana, M., Amato, P., Sparman, M., Woodward, J., Sanchis, D. M., Ma, H. et al. Towards germline gene therapy of inherited mitochondrial diseases. Nature 493 627-631 (2013).

36 Hedrick, P. W. Population genetics of malaria resistance in humans. Heredity 107 283-304 (2011).

37 Gateff, E., Löffler, T. \& Wismar, J. A temperature-sensitive brain tumor suppressor mutation of Drosophila melanogaster: developmental studies and molecular localization of the gene. Mech. Dev. 41, 15-31 (1993).

38 Dani, S. U., Dani, M. A. \& Simpson, A. J. The common mitochondrial DNA deletion deltamtDNA(4977): shedding new light on the concept of a tumor suppressor mutation. Med. Hypotheses 61, 60-63 (2003).

39 Manning, K., Al-Dhalimy, M., Finegold, M. \& Grompe, M. In vivo suppressor mutations correct a murine model of hereditary tyrosinemia type I. Proc. Natl. Acad. Sci. USA 96, 11928-11933 (1999).

40 Furney, S. J., Alba, M. M. \& Lopez-Bigas, N. Differences in the evolutionary history of disease genes affected by dominant or recessive mutations. BMC Genomics 7, 165 (2006).

41 Osada, N., Mano, S. \& Gojobori, J. Quantifying dominance and deleterious effect on human disease genes. Proc. Natl. Acad. Sci. USA 106, 841-846 (2009).

42 Sebro, R., Hoffman, T. J., Lange, C., Rogus, J. J. \& Risch, N. J. Testing for nonrandom mating: evidence for ancestry-related assortative mating in the Framingham heart study. Genet. Epidemiol. 34, 674-679 (2010).

43 Bell, C. J., Dinwiddie, D. L., Miller, N. A., Hateley, S. L., Ganusova, E. E., Mudge, J. et al. Carrier testing for severe childhood recessive diseases by next-generation sequencing. Sci. Transl. Med. 12, 65ra4 (2011).

44 Kingsmore, S. F. \& Saunders, C. J. Deep sequencing of patient genomes for disease diagnosis: when will it become routine? Sci Trans/ Med 3, 87ps23 (2011).

45 Morton, N. E., Crow, J. F. \& Muller, H. J. An estimate of the mutational damage in man from data on consanguineous marriages. Proc. Natl. Acad. Sci. USA 42, 855-863 (1956).

46 Cooper, D. N., Chen, J. M., Ball, E. V., Howells, K., Mort, M., Phillips, A. D. et al. Genes, mutations, and human inherited disease at the dawn of the age of personalized genomics. Hum. Mutat. 31, 631-655 (2010).

47 Asthana, S., Noble, W. S., Kryukov, G., Grant, C. E., Sunyaev, S. \& Stamatoyannopoulos, J. A. Widely distributed noncoding purifying selection in the human genome. Proc. Natl Acad. Sci. USA 104, 12410-12415 (2007).

48 Drake, J. A., Bird, C., Nemesh, J., Thomas, D. J., Newton-Cheh, C., Reymond, A. et al. Conserved noncoding sequences are selectively constrained and not mutation cold spots. Nat. Genet. 38, 223-227 (2006).

49 Parker, S. C., Hansen, L., Abaan, H. O., Tullius, T. D. \& Margulies, E. H. Local DNA topography correlates with functional noncoding regions of the human genome. Science 324, 389-392 (2009).

50 Ponting, C. P. \& Lunter, G. Signatures of adaptive evolution within human noncoding sequence. Hum. Mol. Genet. 15, R170-R175 (2006).

51 Jordan, I. K., Rogozin, I. B., Glazko, G. V. \& Koonin, E. V. Origin of a substantial fraction of human regulatory sequences from transposable elements. Trends Genet. 19, 68-72 (2003).

52 Akagi, K., Li, J. \& Symer, D. E. How do mammalian transposons induce genetic variation? A conceptual framework: the age, structure, allele frequency, and genome context of transposable elements may define their wide-ranging biological impacts. Bioessays 35, 397-407 (2013)

53 Baillie, J. K., Barnett, M. W., Upton, K. R., Gerhardt, D. J., Richmond, T. A., De Sapio, F. et al. Somatic retrotransposition alters the genetic landscape of the human brain. Nature 479, 534-537 (2011).

54 Muller, H. J. Genetic principles in human populations. Am. J. Psychiatry 113, 481-491 (1956).

55 Zhou, S. R. \& Pannell, J. R. Inbreeding depression and genetic load at partially linked loci in a metapopulation. Genet. Res. (Camb.) 92, 127-140 (2010).

56 Campbell, H., Rudan, I., Bittles, A. H. \& Wright, A. F. Human population structure, genome autozygosity and human health. Genome Med. 1, 91 (2009).
57 Almal, S. H. \& Padh, H. Implications of gene copy-number variation in health and diseases. J. Hum. Genet. 57, 6-13 (2012)

58 Zhang, F., Gu, W., Hurles, M. E. \& Lupski, J. R. Copy number variation in human health, disease, and evolution. Annu. Rev. Genomics. Hum. Genet. 10, 451-481 (2009).

59 Gibson, J., Morton, N. E. \& Collins, A. Extended tracks of homozygosity in outbred human populations. Hum. Mol. Genet. 15, 789-795 (2006).

60 Ku, C. S., Naidoo, N., Teo, S. M. \& Pawitan, Y. Regions of homozygosity and their impact on complex diseases and traits. Hum. Genet. 129, 1-15 (2011).

61 Charlesworth, D. \& Willis, J. H. The genetics of inbreeding depression. Nat. Rev. Genet. 10, 783-796 (2009).

62 Rudan, I., Campbell, H., Carothers, A. D., Hastie, N. D. \& Wright, A. F. Contribution of consanguinuity to polygenic and multifactorial diseases. Nat. Genet. 38, 1224-1225 (2006).

63 Frazer, K. A., Murray, S. S., Schork, N. J. \& Topol, E. J. Human genetic variation and its contribution to complex traits. Nat. Rev. Genet. 10, 241-251 (2009).

64 Nakamura, Y. DNA variations in human and medical genetics: 25 years of my experience. J. Hum. Genet. 54, 1-8 (2009).

65 Ku, C. S., Loy, E. Y., Salim, A., Pawitan, Y. \& Chia, K. S. The discovery of human genetic variations and their use as disease markers: past, present and future. J. Hum. Genet. 55, 403-415 (2010).

66 Lippman, Z. B. \& Zamir, D. Heterosis: revisiting the magic. Trends Genet. 23, 60-66 (2007).

67 Glémin, S. Surprising fitness consequences of GC-biased gene conversion. II Heterosis. Genetics 187, 217-227 (2011).

68 Quintana, P. J., Neuwirth, E. A. \& Grosovsky, A. J. Interchromosomal gene conversion at an endogenous human cell locus. Genetics 158, 757-767 (2001).

69 Baker, M. D., Pennell, N., Bosnovan, L. \& Shulman, M. J. Homologous recombination can restore normal immunoglobulin production in a mutant hybridoma cell line. Proc. Natl Acad. Sci. USA 85, 6432-6436 (1988).

70 Stachelek, J. L. \& Liskay, R. M. Accuracy of intrachromosomal gene conversion in mouse cells. Nucleic Acids Res. 16, 4069-4076 (1988).

71 Jeffreys, A. J. \& May, C. A. Intense and highly localized gene conversion activity in human meiotic crossover hot spots. Nat. Genet. 36, 151-156 (2004)

72 Chen, J. M., Cooper, D. N., Chuzhanova, N., Férec, C. \& Patrinos, G. P. Gene conversion: mechanisms, evolution and human disease. Nat. Rev. Genet. 8, 762-775 (2007)

73 Fox, C. W., Scheibly, K. L. \& Reed, D. H. Experimental evolution of the genetic load and its implications for the genetic basis of inbreeding depression. Evolution 62, 2236-2249 (2008)

74 Visscher, P. M., Smith, D., Hall, S. J. G. \& Williams, J. L. A viable herd of genetically uniform cattle. Nature 409, 303 (2001).

75 Denic, S., Nagelkerke, N. \& Agarwal, M. M. On some novel aspects of consanguineous marriages. Public Health Genomics 14, 162-168 (2011).

76 Hamamy, H. \& Bittles, A. H. Genetic clinics in Arab communities: meeting individual, family, and community needs. Public Health Genomics 12, 30-40 (2009).

77 Medawar, P. B. The genetic improvement of man. Australas. Ann. Med. 18, 317-320 (1969).

78 Medawar, P. B. in The Hope of Progress (Methuen, 1972) reprinted in Medawar PB: The Threat and the Glory - Reflections on Science and Scientists (ed. Pyke, D.) 102-109 (Oxford University Press, Oxford, 1991).

79 Vogel, F. Clinical consequences of heterozygosity for autosomal-recessive diseases. Clin. Genet. 25, 381-415 (1984).

801000 Genomes Project ConsortiumAbecasis, G. R., Auton, A., Brooks, L. D., DePristo, M. A., Durbin, R. M., Handsacker, R. E. et al. An integrated map of genetic variation from 1092 human genomes. Nature 491, 56-65 (2012).

81 Morgan, M. T. Genome-wide deleterious mutation favors dispersal and species integrity. Heredity (Edinb) 89, 253-257 (2002).

82 Rudan, I., Carothers, A. D., Polasek, O., Hayward, C., Vitart, V., Biloglav, Z. et al. Quantifying the increase in average human heterozygosity due to urbanisation. Eur. J. Hum. Genet. 16, 1097-1102 (2008).

83 Campbell, H., Carothers, A. D., Rudan, I., Hayward, C., Biloglav, Z., Barac, L. et al Effects of genome-wide heterozygosity on a range of biomedically relevant human quantitative traits. Hum. Mol. Genet. 16, 233-241 (2007).

84 Bittles, A. H. \& Black, M. L. Evolution in health and medicine Sackler colloquium consanguinity, human evolution, and complex diseases. Proc. Natl Acad. Sci. USA 107 (suppl. 1), 1779-1786 (2010).

85 Mingroni, M. A. Resolving the IQ paradox: heterosis as a cause of the Flynn effect and other trends. Psychol. Rev. 114, 806-829 (2007).

86 Jungst, S. B., Kuhlers, D. L. \& Little, J. A. Heterosis losses resulting from incorrect matings in a three-breed rotational crossbreeding system in pigs. J. Anim. Sci. 76 , 29-35 (1998).

87 Thornton, T., Tang, H., Hoffmann, T. J., Ochs-Balcom, H. M., Caan, B. J. \& Risch, N. Estimating kinship in admixed populations. Am. J. Hum. Genet. 91, 122-138 (2012).

88 Dobzhansky, T. Changing man. Science 155, 409-415 (1967).

89 Wolański, N. Assortative mating in somatic traits and its consequences. Stud. Hum. Ecol. 11, 73-111 (1994).

90 Engström, K. S., Hossain, M. B., Lauss, M., Ahmed, S., Raqib, R., Vahter, M. et al. Efficient arsenic metabolism-the AS3MT haplotype is associated with DNA methylation and expression of multiple genes around AS3MT. PLoS One 8, e53732 (2013). 
91 Schlebusch, C. M., Lewis, C. M. Jr, Vahter, M., Engström, K., Tito, R. Y., Obregón-Tito, A. J. et al. Possible positive selection for an arsenic-protective haplotype in humans. Environ. Health. Perspect. 121, 53-58 (2013).

92 Dani, S. U. Gold, coal and oil. Med. Hypotheses 74, 534-541 (2010).

93 Hong, S., Lee, K., Hou, S., Hur, S. D., Ren, J., Burn, L. J. et al. An 800-year record of atmospheric As, Mo, Sn, and Sb in central Asia in high-altitude ice cores from Mt. Qomolangma (Everest), Himalayas. Environ. Sci. Technol. 43, 8060-8065 (2009).

94 Tellez-Plaza, M., Gribble, M. O., Voruganti, V. S., Francesconi, K. A., Goessler, W., Umans, J. G. et al. Heritability and preliminary genome-wide linkage analysis of arsenic metabolites in urine. Environ. Health. Perspect. 121, 345-351 (2013).

95 ten Bosch, J. R. \& Grody, W. W. Keeping up with the next generation: massively parallel sequencing in clinical diagnostics. J. Mol. Diagn. 10, 484-492 (2008).

96 Voelkerding, K. V., Dames, S. A. \& Durtschi, J. D. Next-generation sequencing: from basic research to diagnostics. Clin. Chem. 55, 641-658 (2009).

97 Kaye, J., Boddington, P., de Vries, J., Hawkins, N. \& Melham, K. Ethical implications of the use of whole genome methods in medical research. Eur. J. Hum. Genet. 18 398-403 (2010).

98 Ethics Committee of the American Society for Reproductive Medicine. Use of preimplantation genetic diagnosis for serious adult onset conditions: a committee opinion. Fertil. Steril. pii S0015-0282, 00342-00347 (2013).

99 Arélin, M., Schulze, B., Müller-Myhsok, B., Horn, D., Diers, A., Uhlenberg, B. et al. Genome-wide linkage analysis is a powerful prenatal diagnostic tool in families with unknown genetic defects. Eur. J. Hum. Genet. 21, 367-372 (2013).

100 Bell, C. J., Dinwiddie, D. L., Miller, N. A., Hateley, S. L., Ganusova, E. E., Mudge, J. et al. Carrier testing for severe childhood recessive diseases by next-generation sequencing. Sci. Transl. Med. 3, 65ra64 (2011).

101 Jackson, L. \& Pyeritz, R. E. Molecular technologies open new clinical genetic vistas. Sci. Transl. Med. 3, 65ps62 (2011).

102 Aparicio, J. M., Ortego, J. \& Cordeiro, P. J. Can a simple algebraic analysis predict markers-genome heterozygosity correlations? J. Heredity 98, 93-96 (2007).

$103 \mathrm{Nei}, \mathrm{M}$. Modification of linkage intensity by natural selection. Genetics $\mathbf{5 7}, \mathbf{6 2 5 - 6 4 1}$ (1967).

104 Nei, M. Evolutionary change of linkage intensity. Nature 218, 1160-1161 (1968).

105 Watson, R. A., Weinreich, D. M. \& Wakeley, J. Genome structure and the benefit of sex. Evolution 65, 523-536 (2011).

106 de Visser, J. A. \& Elena, S. F. The evolution of sex: empirical insights into the roles of epistasis and drift. Nat. Rev. Genet. 8, 139-149 (2007).

107 Morgan, T. H., Sturtevant, A. H., Muller, H. J. \& Bridges, C. B. The Mechanism of Mendelian Heredity (Henry Holt, New York, 1915).

108 Jeffreys, A. J., Holloway, J. K., Kauppi, L., May, C. A., Neumann, R., Slingsby, M. K. et al. Meiotic recombination hot spots and human DNA diversity. Philos. Trans. R. Soc. Lond. B Biol. Sci. 359, 141-152 (2004).

109 Coop, G., Wen, X., Ober, C., Pritchard, J. K. \& Przeworski, M. High-resolution mapping of crossovers reveals extensive variation in fine-scale recombination patterns among humans. Science 319, 1395-1398 (2008).

110 Kong, A., Thorleifsson, G., Gudbjartsson, D. F., Masson, G., Sigurdsson, A., Jonasdottir, A. et al. Fine-scale recombination rate differences between sexes, populations and individuals. Nature 467, 1099-1103 (2010).

111 Khil, P. P. \& Camerini-Otero, R. D. Genetic crossovers are predicted accurately by the computed human recombination map. PLoS. Genet. 6, e1000831 (2010).

112 Hedges, D. J. \& Belancio, V. P. Restless genomes: humans as a model organism for understanding host-retrotransposable element dynamics. Adv. Genet. 73, 219-262 (2011).

113 O’Donnell, K. A. \& Burns, K. H. Mobilizing diversity: transposable element insertions in genetic variation and disease. Mob. DNA 1, 21 (2010).

114 Campbell, R. B. The effects of genetic screening and assortative mating on lethal recessive-allele frequencies and homozygote incidence. Am. J. Hum. Genet. 41, 671-677 (1987).

115 Rumyantsev, S. N. Obesity: a reckoning both for genetic immunity to infection and xenogamy. Med. Hypotheses 66, 535-540 (2006).

116 Rumyantsev, S. N. The uniqueness and ordinariness of cancer origin and pathogenesis: new epidemiological, clinical and preventive perspectives. J. Clin. Med. Res. 1, 32-36 (2009).

117 Galton, F. Eugenics: its definition, scope and aims. Am. J. Sociol. 10, 1-25 (1904).

118 Aultman, J. M. Eugenomics: eugenics and ethics in the 21 st century. Genom. Soc. Policy 2, 28-49 (2006).

119 Richards, M. Artificial insemination and eugenics: celibate motherhood, eutelegenesis and germinal choice. Stud. Hist. Philos. Biol. Biomed. Sci. 39, 211-221 (2008).

120 Missa, J. N. From state eugenics to private eugenics. Baillieres Best Pract. Res. Clin. Obstet. Gynaecol. 13, 533-541 (1999).

121 Allen, G. E. Essays on science and society. Is a new eugenics afoot? Science 294, 59-61 (2001).

122 Bondi, S. Access to medical-assisted reproduction and PGD in Italian law: a deadly blow to an illiberal statute? Commentary to the European Court on Human Right's decision Costa and Pavan V Italy (ECtHR, 28 August 2012, App. 54270/2010). Med. Law Rev.e-pub ahead of print (3 April 2013).

123 Medawar, P. B. The Future of Man. BBC Reith Lectures 1959. Methuen, 1960; reproduced in The Threat and the Glory 110-196 (Oxford University Press, Oxford, 1990).

124 Wedekind, C., Seebeck, T., Bettens, F. \& Paepke, A. J. MHC-dependent mate preferences in humans. Proc. Biol. Soc. 260, 245-249 (1995).
125 Wedekind, C. \& Füri, S. Body odour preferences in men and women: do they aim for specific MHC combinations or simply heterozygosity? Proc. Biol. Soc. 264, 1471-1479 (1997)

126 Black, F. L. \& Pandey, J. P. Evidence for balancing of KM, but not GM alleles by heterotic advantage in South Amerinds. Hum. Genet. 100, 240-244 (1997).

127 Hellemann, D., Larsson, A., Madsen, H. O., Bonde, J., Jarløv, J. O., Wiis, J. et al. Heterozygosity of mannose-binding lectin (MBL2) genotypes predicts advantage (heterosis) in relation to fatal outcome in intensive care patients. Hum. Mol. Genet. 16, 3071-3080 (2007).

128 Edler, R. J. \& Orth, M. Background consideration to facial aesthetics. J. Orthod. 28 159-168 (2001).

129 Harshman, L. G., Müller, H. G., Liu, X., Wang, Y. \& Carey, J. R. The symmetry of longevity. J. Gerontol. A Biol. Sci. Med. Sci. 60, 1233-1237 (2005).

130 Chung, C. S., Niswander, J. D., Runck, D. W., Bilben, S. E. \& Kau, M. C. Genetic and epidemiologic studies of oral characteristics in Hawaii's schoolchildren. II. Malocclusion. Am. J. Hum. Genet. 23, 471-495 (1971).

131 Happle, R. Loss of heterozygosity in human skin. J. Am. Acad. Dermatol. 41 (2 Pt 1), 143-164 (1999).

$132 \mathrm{Kamb}, \mathrm{A}$. Consequences of nonadaptive alterations in cancer. Mol. Biol. Cell. 14, 2201-2205 (2003).

133 Hartl, D. L. \& Clarke, A. G. Principles of Population Genetics (Sinauer, Sunderland, $M A, 2007)$.

134 Kondrashov, A. S. \& Shpak, M. On the origin of species by means of assortative mating. Proc. Biol. Sci. 265, 2273-2278 (1998).

135 Tregenza, T. \& Wedell, N. Genetic compatibility, mate choice and patterns of parentage: invited review. Mol. Ecol. 9, 1013-1027 (2000).

136 vanDoorn, G. S., Edelaar, P. \& Weissing, F. J. On the origin of species by natural and sexual selection. Science 326, 1704-1707 (2009).

$137 \mathrm{Nei}$, M., Maruyama, T. \& Wu, C. I. Models of evolution of reproductive isolation. Genetics 103, 557-579 (1983).

138 Harpending, H. \& Cochran, G. Genetic diversity and genetic burden in humans. Infect. Genet. Evol. 6, 154-162 (2006).

139 Otto, S. P., Servedio, M. R. \& Nuismer, S. L. Frequency-dependent selection and the evolution of assortative mating. Genetics 179, 2091-2112 (2008).

140 Kruglyak, L. \& Nickerson, D. A. Variation is the spice of life. Nat. Genet. 27, 234-236 (2001).

141 Keightley, P. D. \& Otto, S. P. Interference among deleterious mutations favours sex and recombination in finite populations. Nature 443, 89-92 (2006).

142 Leighton, J. W., Valverde, K. \& Bernhardt, B. A. The general public's understanding and perception of direct-to-consumer genetic test results. Public Health Genomics 15, 11-21 (2012).

143 Ducournau, P., Gourraud, P.-A., Rial-Sebbag, E., Bulle, A. \& Cambon-Thomsen, A. Tests génétiques en accès libre sur Internet: Stratégies commerciales et enjeux éthiques et sociétaux. Méd./Sci. 27, 95-102 (2011).

144 Janssens, A. C. J. W., Gwinn, M., Subramonia-lyer, S. \& Khoury, M. J. Does genetic testing really improve the prediction of future type 2 diabetes? PLOS Med. 3, e114 (2006).

145 Lederberg, J. Molecular biology, eugenics and euphenics. Nature 198, 428-429 (1963).

146 Wiesenfeld, S. L. Sickle-cell trait in human biological and cultural evolution. Development of agriculture causing increased malaria is bound to gene-pool changes causing malaria reduction. Science 157, 1134-1140 (1967).

147 Jones, T. Quantitative aspects of the relationship between the sickle-cell gene and malaria. Parasitol. Today 13, 107-111 (1997).

148 Hanchard, N. A., Hambleton, I., Harding, R. M. \& McKenzie, C. A. Predicted declines in sickle allele frequency in Jamaica using empirical data. Am. J. Hematol. 81, 817-823 (2006).

149 Neel, J. F. Diabetes mellitus: a 'thrifty' genotype rendered detrimental by 'progress'? Am. J. Hum. Genet. 14, 353-362 (1962).

150 Dowse, G. K., Zimmet, P. Z., Finch, C. F. \& Collins, V. R. Decline in incidence of epidemic glucose intolerance in Nauruans: implications for the "thrifty genotype". Am. J. Epidemiol. 133, 1093-1104 (1991).

151 Dani, S. U., Dani, M. A., Freire, I. L., Gouvea, S. P., Knackfuss, F. B., Lima, F. P. et al. Survival of the thriftiest: restricted nurture reveals the thrifty nature of a growth gene in Bos indicus. Genet. Mol. Res. 9, 1032-1044 (2010).

152 Khoury, M. J. \& Wacholder, S. Invited commentary: from genome-wide association studies to gene-environment-wide interaction studies-challenges and opportunities. Am. J. Epidemiol. 169, 227-230 (2009).

153 European Society of Human Genetics. Statement of the ESHG on direct-to-consumer genetic testing for health-related purposes. Eur. J. Hum. Genet. 18, 1271-1273 (2010).

154 ASRM. Preimplantation genetic testing: a practice committee opinion. Fertil. Steril. 90 (suppl. 3), S136-S144 (2008).

155 Goossens, V., Harton, G., Moutou, C., Traeger-Synodinos, J., Rij, M. \& Harper, J. C. ESHRE PGD Consortium data collection IX: cycles from January to December 2006 with pregnancy follow-up to October 2007. Hum. Reprod. 24, 1786-1810 (2009).

156 Rhodes, R. Why test children for adult-onset genetic diseases? Mt. Sinai. J. Med. 73, 609-616 (2006).

157 American Academy of Pediatrics, Committee on Bioethics. Ethical issues with genetic testing in pediatrics. Pediatrics 107, 1451-1455 (2001).

158 Baruch, S. Preimplantation genetic diagnosis and parental preferences: beyond deadly disease. Houst. J. Health. Law. Policy. 8, 245-270 (2008). 
159 Bunnik, E. M., Shermer, M. H. \& Janssens, A. C. Personal genome testing: test characteristics to clarify the discourse on ethical, legal and societal issues. BMC Med. Ethics 12, 11 (2011).

160 Evans, J. P. Health care in the age of genetic medicine. JAMA 298, 2670-2672 (2007).

161 Wise, P. H. Emerging technologies and their impact on disability. Future Child. 22, 169-191 (2012).

162 Snell, K., Starkbaum, J., Lauß, G., Vermeer, A. \& Helén, I. From protection of privacy to control of data streams: a focus group study on biobanks in the information society. Public Health Genomics 15, 293-302 (2012).

163 Wade, C. H., Shiloh, S., Roberts, J. S., Hensley Alford, S., Marteau, T. M. \& Biesecker, B. B. Preferences among diseases on a genetic susceptibility test for common health conditions: an ancillary study of the multiplex initiative. Public Health Genomics 15, 322-326 (2012).

164 Fowler, J. H., Settle, J. E. \& Christakis, N. A. Correlated genotypes in friendship networks. Proc. Natl Acad. Sci. USA 108, 1993-1997 (2011).

165 Medawar, P. B. The Future of Man. BBC Reith Lectures 1959. Methuen, York, 1960. Reproduced in The Threat and the Glory 132 (Oxford University Press, Oxford 1991).

166 Pearce, N. Commentary: the rise and rise of corporate epidemiology and the narrowing of epidemiology's vision. Int. J. Epidemiol. 36, 713-717 (2007).

167 McCarthy, M. I., Abecasis, G. R., Cardon, L. R., Goldstein, D. B., Little, J., Ioannidis, J. P. et al. Genome-wide association studies for complex traits: consensus, uncertainty and challenges. Nat. Rev. Genet. 9, 356-369 (2008). 